\title{
Extensive Analysis of Multi Strand Billet Caster Tundish Using Numerical Technique
}

\author{
Rohit Agarwal, Mrityunjay K. Singh*, Ram Bachchan Kumar, Biswajit Ghosh, Sudhansu Pathak \\ Tata Steel Limited, Jamshedpur, India \\ Email: ^rohit.agarwal1@tatatseel.com, mrityunjay.singh@tatatseel.com,rbkumar@tatasteel.com, biswajitg@tatasteel.com, \\ sudhansupathak@tatasteel.com
}

How to cite this paper: Agarwal, R., Singh, M.K., Kumar, R.B., Ghosh, B. and Pathak, S. (2019) Extensive Analysis of Multi Strand Billet Caster Tundish Using Numerical Technique. World Journal of Mechanics, 9, 29-51.

https://doi.org/10.4236/wjm.2019.92003

Received: October 12, 2018

Accepted: February 10, 2019

Published: February 13, 2019

Copyright $\odot 2019$ by author(s) and Scientific Research Publishing Inc. This work is licensed under the Creative Commons Attribution International License (CC BY 4.0).

http://creativecommons.org/licenses/by/4.0/

(c) (i) Open Access

\begin{abstract}
Continuous casting of steel involving different grades in the same casting sequence remains a challenge to billet caster operators. The intermixed composition obtained during the grade change does not meet the specification of either grade and must be downgraded. Incorrect identification of this intermixed region may result in non-conforming products reaching the customer. In this study, a numerical model based on CFD (computational fluid dynamics approach) has been developed which predicts the start and end of the intermixed composition and the tonnage to be downgraded under different casting conditions. This model was validated and the results were in good agreement with the actual plant data for a 6-strand billet caster at LD-1 of TATA Steel, India. This model is used to calculate transition tonnage for different scenarios, e.g. when one of the outermost strands is not functional or some combinations are not functional and varying casting speed during operation. Furthermore, impact of different design of baffles on performance of Tundish has been evaluated to find a way to reduce transition or intermixed composition.
\end{abstract}

\section{Keywords}

Continuous Casting, CFD, Billet, Tundish, Grade Change, Modelling, Quality Control, Fluid Flow, Heat Transfer

\section{Introduction}

Continuous casting of steel involves liquid steel to be transferred from ladle to Tundish and finally to mould. The mould provides desired shape, where partial solidification of liquid steel happens. The Tundish works as a buffer between mould and ladle. Tundish provides two functional requirements: inclusion floa- 
tation and equal flow to the moulds [1] and [2] for multi strand caster configurations. The number of moulds is in general 1 to 2 for slab casters, 2 to 4 for bloom casters and 2 to 8 for billet caster [3].

When two heats of different composition are cast in a continuous sequence without replacing the Tundish produces intermixed products or grade transition. In such cases, products with intermixed composition are produced which are neither conformal to either composition and are needed to be diverted or downgraded [4] [5] [6]. The casting operators need to know the location and extent of the intermixed region and how it is affected by grade specifications and casting conditions [3] [5]. With the strict norms for steel grades with specific composition, there is a consequent rise of grade transitions in the casting sequence, thus giving a further increase in the cost associated with the intermixed steel.

For the prediction of the intermixed region due to the transition, different techniques have been developed [1] [2]. Water models [1] [2] [7], 3D numerical models [6] [8] and semi-empirical numerical models [3] are the typical tools to address this problem. But each of the method has its own limitations; for example the water model fails to satisfy both Froude and Reynolds similarity criteria on scaled models to predict the transition. In the three-dimensional numerical modelling [8] [9] [10], it requires an injection of tracer, but the credibility of the model is based on the validation with the plant data [8] [11] [12] [13] [14]. Third case of semi-empirical model is based on experiment on real plant conditions where billet/slab composition is tracked with time to predict transition tonnage. The strong point of this approach is that it is based on real plant condition; however, for multi strand casting especially in billet and bloom casting, it is difficult to perform experiments for different plant condition. It is also important to note that design of Tundish also plays a major role in this and a model developed for a design of Tundish may not be valid for other Tundish designs.

Therefore, in the present work, a three-dimensional numerical model has been developed based on computational fluid dynamics (CFD) for the prediction of transition tonnage for 6 strands billet caster of Tata Steel India. The model is first validated with the available plant data and after the successful validation, the model is used to predict the transition tonnage under different plant conditions when one or more strand is non-functional or to find the effect of different casting speeds.

There is always an emphasis in the industry to reduce the transition tonnage to reduce the losses or diversions. Generally, baffles and weirs have proven to be a factor to reduce intermixed quantity [6] [7] [10]. In this study, two designs of baffles have been analysed to find the efficiency regarding intermixed quantity.

\section{Problem Definition}

As mentioned in the previous section, the scope of the study includes estabilishment of a well validated numerical model for grade transition for caster\#3 
(CC\#3) of Tata Steel and further use this model to predict various scenarios existing in the plant. In addition, a means to minimize grade transition by using special baffle arrangement has also been evaluated. Figure 1(a) shows general schematics of a Tundish with 6 strands. Tata Steel India produces around 3.5 million tons of long products and out which, 1 million tons is produced via caster 3 (CC\#3) route. The Caster 3 covers the range from low carbon, to Thermo-mechanical treatment (TMT) bars to high carbon grades processing (wire and wire rods).

In general, Tundish is a combination of plug flow reactor (PFR) and Continuously stirred tank reactor (CSTR) [14] [15] [16]. During sequence change of the casting, grade change leads to mixing of grades which may be undesirable for critical grades. Grade change leading to transition can be explained as follows, suppose a grade with " $x$ " Composition (Chemistry) is being casted and after a certain time the other grade with Composition " $y$ " is poured in the Tundish with $(y>x)$ [3]. A general picture regarding concentration variation at a strand (outlet from Tundish to inlet of mould) with time can be plotted as shown in Figure 2(a). The concentration plot can be made dimensionless using Equation (1), as shown in Figure 2(b).

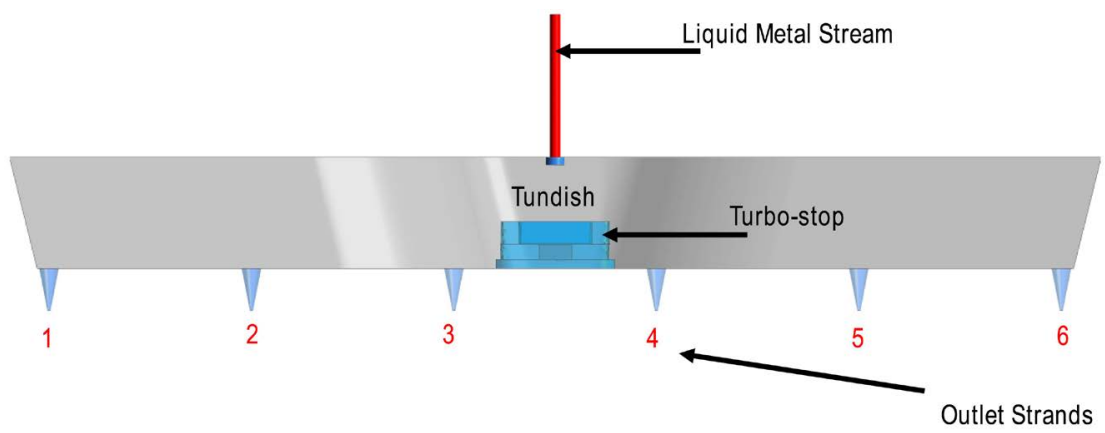

(a)

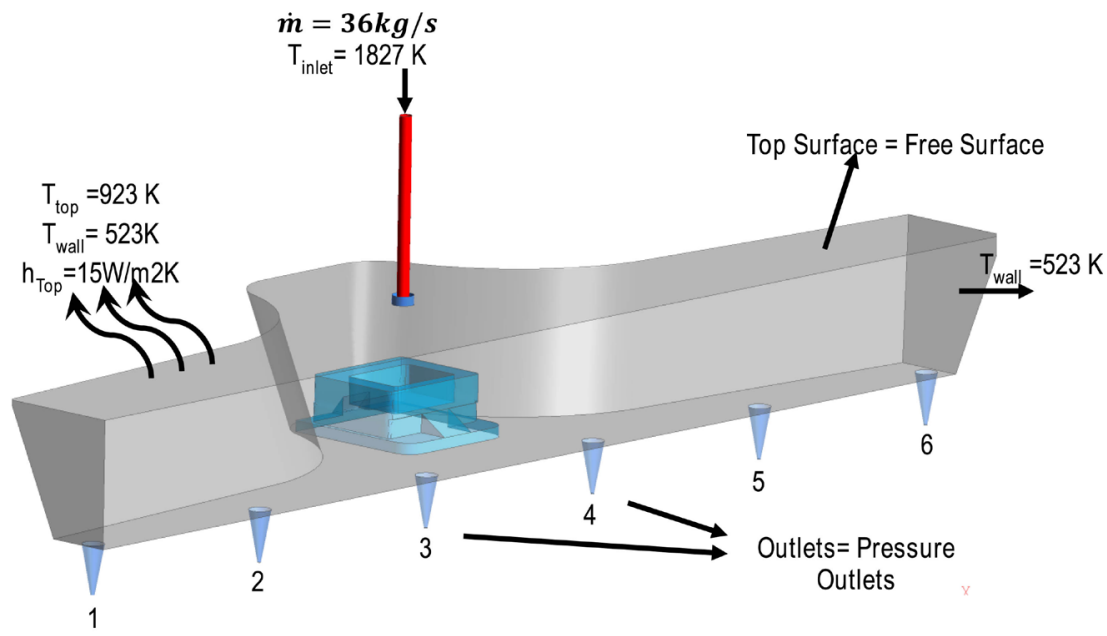

(b)

Figure 1. Geometry and boundary conditions for 6 strand Tundish. (a) Schematics of a 6-Strand Tundish; (b) Boundary conditions for 6 strand billet caster. 


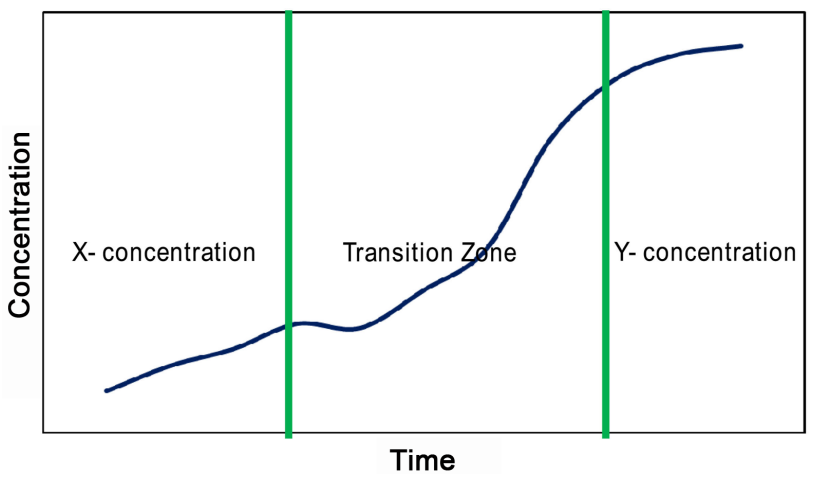

(a)

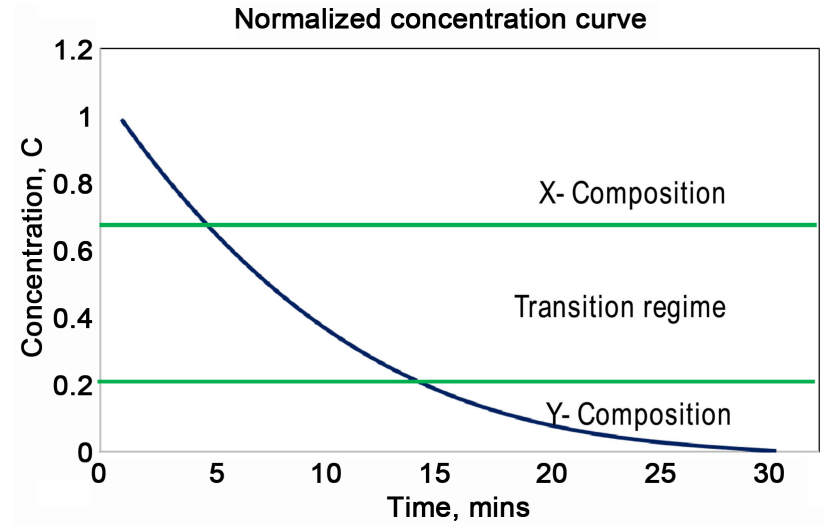

(b)

Figure 2. Concentration variation from grade $x$ to grade $y$. (a) Concentration vs. time; (b) Normalised concentration vs. time.

$$
c^{*}=\frac{c(t)-x}{y-x}
$$

In the equation $c^{*}$ is dimensionless concentration, $c(t)$ is the composition of given element in time $t, x$ and $y$ are the element composition for old and new grade respectively.

Using the above methodology, a concentration plot is obtained for Tundish using CFD model by tracking the concentration of tracer. This forms the basis for calculation of grade transition. The details are outlined in the next section where numerical approach and boundary conditions are provided.

\section{Numerical Approach}

\subsection{Governing Equations}

CFD analysis has been performed to get the flow field and tracer evolution in the Tundish. The underlying equations used for the study are outlined as follows:

- For the mass conservation, continuity equation (Equation (2)) is solved

$$
\frac{\partial \rho V}{\partial t}+\nabla \cdot(\rho V)=0
$$

Here $V$ is the velocity. 
For the momentum balance and heat transfer, Navier-Stokes equation [11] [12] [13] (Equation (3)) and thermal energy equation (Equation (4)) are solved, respectively

$$
\begin{array}{r}
\frac{\partial \rho u}{\partial t}+\nabla \cdot(\rho V \times V)=-\nabla \cdot p+\mu \nabla^{2} V-g \alpha \Delta T \\
\frac{\partial \rho E}{\partial t}+\nabla \cdot(\rho \bar{V}(E+p))=\nabla \cdot k_{e f f} \nabla T
\end{array}
$$

Here $E$ is the energy, $T$ is the temperature, $t$ is the time, $k$ is the effective diffusion term, $p$ is the pressure, $\mu$ is the dynamic viscosity, $g$ is the acceleration due to gravity, $\alpha$ is the thermal expansion coefficient.

Thermal induced buoyancy has been modelled using Boussinesq approximation [11]. This has been added as a source term in the momentum equation (Equation (3)), see the rightmost term of Equation (3). The reference density of steel in Boussineq approximation is taken as $7200 \mathrm{~kg} / \mathrm{m}^{3}$.

- To model turbulence, realizable k- $\varepsilon$ model with enhanced wall treatment has been used. The realizable $\mathrm{k}-\varepsilon$ model with enhanced wall treatment has been found to be better for Tundish flow simulations as mentioned in references [16] [17].

$$
\frac{\partial}{\partial t}(\rho K)+\nabla \cdot(\rho K V)=\nabla \cdot\left[\left(\frac{\mu_{t}}{\sigma_{K}}\right) \nabla K\right]+2 \mu S_{i j} \cdot S_{i j}-\rho \varepsilon
$$

Here $\mu_{t}=\rho C_{\mu} \frac{K^{2}}{\varepsilon}$.

Here $C_{\mu}$ is dimesionless constant and $C_{\mu}=0.09$.

$$
\begin{aligned}
& \frac{\partial}{\partial t}(\rho \varepsilon)+\nabla \cdot(\rho \varepsilon V) \\
& =\nabla \cdot\left[\left(\frac{\mu_{t}}{\sigma_{\varepsilon}}\right) \nabla \varepsilon\right]+\rho C_{1} S_{\varepsilon}-\rho C_{2} \frac{\varepsilon^{2}}{K+\sqrt{v \varepsilon}}+C_{1 \varepsilon} \cdot \frac{\varepsilon}{K} C_{3 \varepsilon} G_{b}
\end{aligned}
$$

where $C_{1}=\left[0.43, \frac{\eta}{\eta+5}\right], \eta=S \cdot \frac{K}{\varepsilon}$ and $S=\sqrt{2 S_{i j} S_{i j}}$.

And value of $C_{1 \varepsilon}=1.44, C_{2}=1.9, \sigma_{K}=1.0$ and $\sigma_{\varepsilon}=1.2$.

The Pressure-Implicit with Splitting of Operators (PISO) [17] algorithm was used for the pressure-velocity coupling and Quadratic Upstream Interpolation for Convective Kinematics (QUICK) [17] scheme was used for the discretization of momentum, energy, turbulent kinetic energy and turbulent dissipation rate equations.

- The strategy to mimic transition of grades during Tundish operation is realized via injecting a tracer for one second (pulse injection of the tracer) and then tracking the evolution of the tracer for longer duration. Note that the tracer is tracked on a developed flow field that is after solving the flow field for more than two times of theoretical residence time [3] [7]. The concentration equation (Equation (7)) is solved to track species concentration over time. The tracer study is similar to injecting a dye in a water models for an 
instant of time and tracking the evolution of dye with time [6].

$$
\frac{\partial \rho_{c} C}{\partial t}+\nabla \cdot(\rho V C)=\nabla \cdot\left(\rho_{c} D_{e} \nabla C\right)
$$

where, $C$ is the species mass fraction $D_{e}$ is effective diffusion which is sum of molecular diffusion and turbulent diffusion. The turbulent diffusion coefficient is determined the turbulent diffusion coefficient is determined from the following relationship (assuming that the turbulent Schmidt number equals unity):

$$
\frac{\partial \rho D_{e}}{\mu_{e}} \sim 1
$$

As mentioned above, the tracer is tracked on the frozen flow field till most of the injected tracer leaves the Tundish via strands/outlets. For each strand/outlet, the concentration variation of the species is tracked with respect to time. This history of concentration variation with respect to time is called RTD (Residence time distribution) curve. In general, aRTD curve is a characteristic function of continuous process system and provides information on malfunction(s) if any and flow pattern i.e. degree of mixing [2] [8] [15] [18].

This RTD curve is further normalized to get the Exit Age distribution curves (E-Curve) [2] [8] [15] [19] [20] as follow:

$$
E(t)=\frac{c(t)-c(t=0)}{\int_{0}^{n}[c(t)-c(t=0)] \mathrm{d} t}
$$

Such that

$$
\int_{0}^{n} E_{i}(t) \mathrm{d} t=1
$$

where, $i=1,2, \cdots, n, c_{i}(t)$ : tracer concentration obtained either from experiment or numerical models and $E_{i}(t)$ : residence time distribution function.

After getting the $E$ curve, further normalization of $E$ curve is done to get normalized concentration $C$ as follow:

$$
C(t)=1-\int_{0}^{n} E_{i}(t) \mathrm{d} t
$$

where $C(t)$ represents the normalized concentration of tracer at time $t$. This normalized concentration $C(t)$ forms the basis for predicting the transition tonnage.

\subsection{Geometry and Boundary Conditions}

The 3-D design of Tundish is as shown in Figure 1(b). It is a six strand Tundish with a turbo stop just beneath the inlet to control turbulence.

Mass flow rate based on casting speed has been provided at the inlet with turbulence intensity of 5\% [9]. The no slip condition was employed on each wall surface with the zero velocity at the wall. The outflow boundary condition was taken at each outlet. The top surface was assumed as a free surface with the zero-shear stress. The acceleration due to gravity was taken as $9.81 \mathrm{~m} / \mathrm{s}^{2}$.

For the heat transfer calculation, the boundary conditions include the incom- 
ing liquid steel temperature as $1823 \mathrm{~K}$. The heat losses were supposed to be taking place through the walls, bottom and free surface of fluid in the Tundish. The heat transfer coefficient at the top surface is taken as $15 \mathrm{~W} / \mathrm{m}^{2} \mathrm{~K}$ and for Tundish walls heat transfer coefficient is taken as $3.46 \mathrm{~W} / \mathrm{m}^{2} \mathrm{~K}$ [9]. The higher heat transfer at top surface is due to extra radiative heat transfer taking place as compared to walls of Tundish where only conductive heat transfer happens.

Further detailed boundary conditions are listed in Table 1. The commercial ANSYS Fluent V.15 has been used in this study.

\section{Grid Independence Study}

A grid independence study has been performed to find the appropriate grid for the Tundish flow. The results were assessed for four different grids: 81,470, $333,320,5,076,362$ and 9,466,023 elements with maximum element size varying from $100 \mathrm{~mm}, 75 \mathrm{~mm}, 45 \mathrm{~mm}$ and $25 \mathrm{~mm}$ respectively.

Table 2 shows the temperature and velocity at outlet number 3 for the above four meshes. Figure 3 shows the temperature value on a line passing through the cross-section of the Tundish along $\mathrm{X}$ axis (6.34 $\mathrm{m}$ domain). The difference in average results for velocity at outlet 3 for 81,470 elements and 9,466,023 elements is about $10 \%$ while the difference in the results for 5,076,362 elements and $9,466,023$ elements is about $1 \%$. Therefore, in the present study, the $3-\mathrm{D}$ computational grid having 5,076,362 has been considered.

Table 1. Boundary conditions for 6 strand Tundish.

\begin{tabular}{|c|c|c|}
\hline Parameter & Unit & Tundish \\
\hline No. of strands & {$[-]$} & 6 \\
\hline Casting speed & {$[\mathrm{m} / \mathrm{min}]$} & 3 \\
\hline Mass flow rate & {$[\mathrm{Kg} / \mathrm{s}]$} & 36 \\
\hline Mass flow rate & [Metric Ton/minute] & 2.16 \\
\hline Volume & {$\left[\mathrm{m}^{3}\right]$} & 4.1 \\
\hline Total liquid steel & [Metric Ton] & 32 \\
\hline Theoretical residence time & {$[\mathrm{s}]$} & 900 \\
\hline Shroud internal diameter & {$[\mathrm{m}]$} & 0.067 \\
\hline Outlet nozzle diameter & {$[\mathrm{m}]$} & 0.018 \\
\hline Submergence depth of the shroud & {$[\mathrm{m}]$} & 0.05 \\
\hline Temperature of inlet stream $\left(\mathrm{T}_{\text {in }}\right)\left[{ }^{*}\right.$ during trial $]$ & {$[\mathrm{K}]$} & 1823 \\
\hline Heat transfer coefficient at Tundish top $\left(\mathrm{h}_{\mathrm{top}}\right)$ & {$\left[\mathrm{W} / \mathrm{m}^{2} \mathrm{~K}\right]$} & 15 \\
\hline Heat transfer coefficient at Tundish top $\left(\mathrm{h}_{\text {walls }}\right)$ & {$\left[\mathrm{W} / \mathrm{m}^{2} \mathrm{~K}\right]$} & 3.46 \\
\hline Temperature of top wall ( $\left.\mathrm{T}_{\text {top }}\right)$ & {$[\mathrm{K}]$} & 1200 \\
\hline Temperature of side walls $\left(\mathrm{T}_{\text {sides }}\right)$ & {$[\mathrm{K}]$} & 523 \\
\hline Density of liquid stream and Tracer & {$\left[\mathrm{kg} / \mathrm{m}^{3}\right]$} & 7200 \\
\hline Conductivity of liquid steel & {$[\mathrm{W} / \mathrm{mk}]$} & 35 \\
\hline Specific heat capacity of liquid steel & {$[\mathrm{J} / \mathrm{kg} \cdot \mathrm{k}]$} & 640 \\
\hline
\end{tabular}


Temperature plot for mesh validation

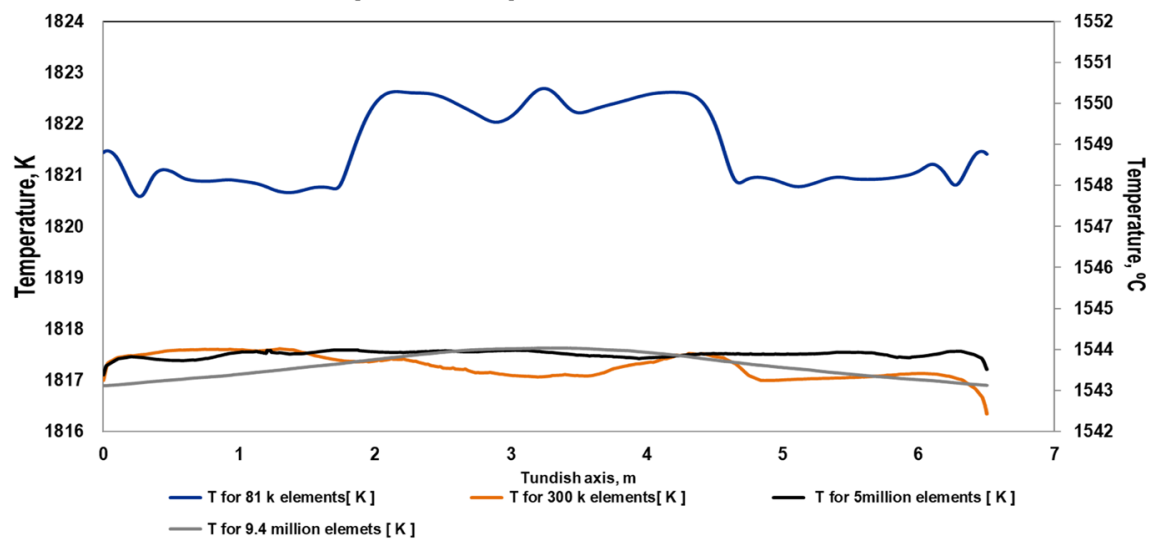

Figure 3. Temperature on a line along length of Tundish for the grid independence.

Table 2. Mesh validation for Tundish grade transition.

\begin{tabular}{ccc}
\hline No. of Cells & Velocity at Outlet $\mathbf{3}(\mathrm{m} / \mathrm{s})$ & Temperature at outlet $\mathbf{3}(\mathrm{K})$ \\
\hline 81470 & 3.528 & 1815.255 \\
333320 & 3.411 & 1816.047 \\
$\mathbf{5 0 7 6 3 6 2}$ & 3.248 & $\mathbf{1 8 1 6 . 8 7 1}$ \\
9466023 & 3.235 & 1817.298 \\
\hline
\end{tabular}

\section{Results and Discussion}

This section will describe the important results and validation aspects of this work.

\subsection{Flow Features in the Tundish}

To understand the general flow feature of the Tundish, flow pattern, temperature field contours and velocity vectors are visualized at different planes. Figures 4-6 show the velocity contour, vectors, and streamlines respectively for $3 \mathrm{~m} / \mathrm{min}$ $(0.05 \mathrm{~m} / \mathrm{s})$ casting speed for 28 Ton $(28,000 \mathrm{~kg})$ Tundish weight (total liquid steel content in the Tundish).

Based on the contours, vectors and streamlines, it is visible that flow is predominantly surface driven; this is evident by the presence of high velocity near top of the Tundish spanning across the width. Just below this high velocity zone, there exist many slow-moving zones or say slow moving islands (see the blue coloured region in the contour plots and the recirculation loop marked by arrows in the vector plot (Figure 4(a))). A noteworthy observation is that, see Figure 5, a high velocity zone is present near the top surface of the rear end of Tundish and this high velocity zone propagates very near to rear wall spanning the whole width. This can provide a clue that there can be erosion issue at rear side of wall due to this high velocity.

To understand flow and short-circuiting phenomena, snapshots of streamline are plotted for different intervals as shown in Figure 6. It is evident from initial 


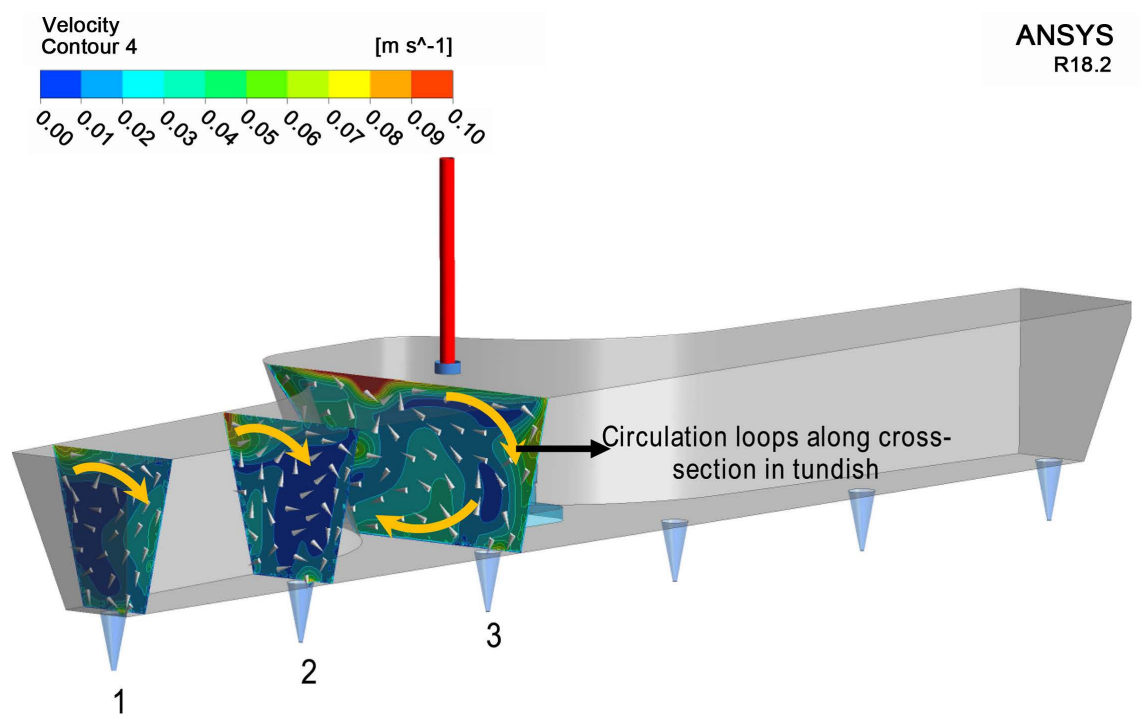

(a)

$$
\begin{aligned}
& \text { Velocity } \\
& \text { [m s^-1] }
\end{aligned}
$$

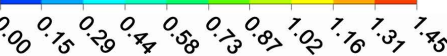

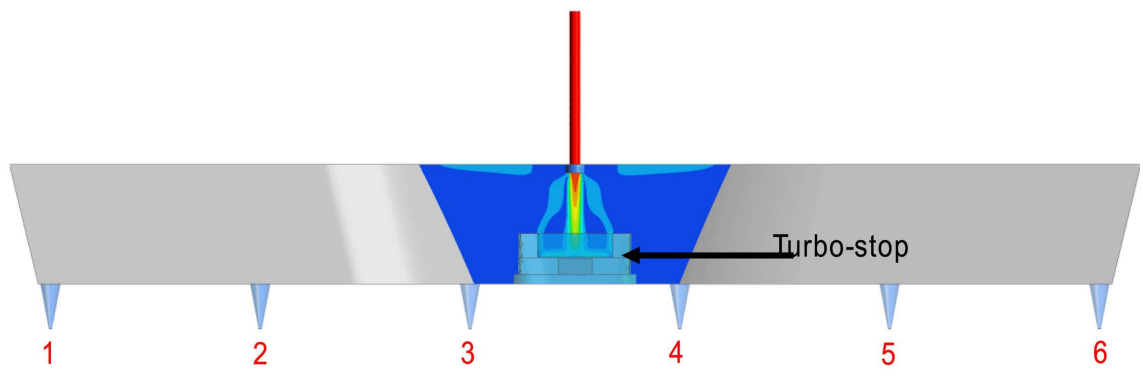

(b)
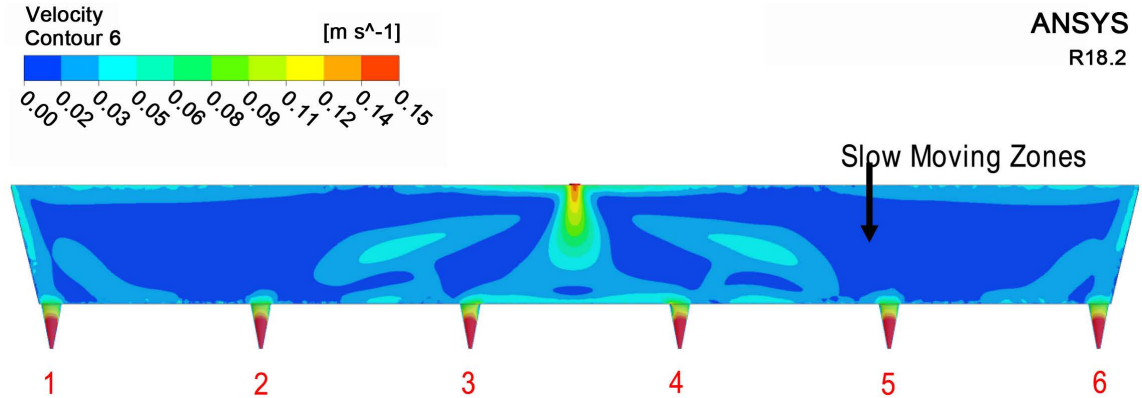

(c)

Figure 4. Velocity contours on various planes in 6 strands Tundish for all strands running. (a) Velocity field on a plane across the Tundish near three outlets for 6 strand Tundish; (b) Velocity field on a plane passing through the inlet for 6 strand Tundish; (c) Velocity field on a plane passing through all outlets for 6 strand Tundish.

streamline paths that there are heavy recirculation zones near inlet due to special curved refractory design near the inlet part. Based on streamline, a fair judgment can be done on short circuiting, see Figure 6(b) and Figure 6(c). It is obvious 


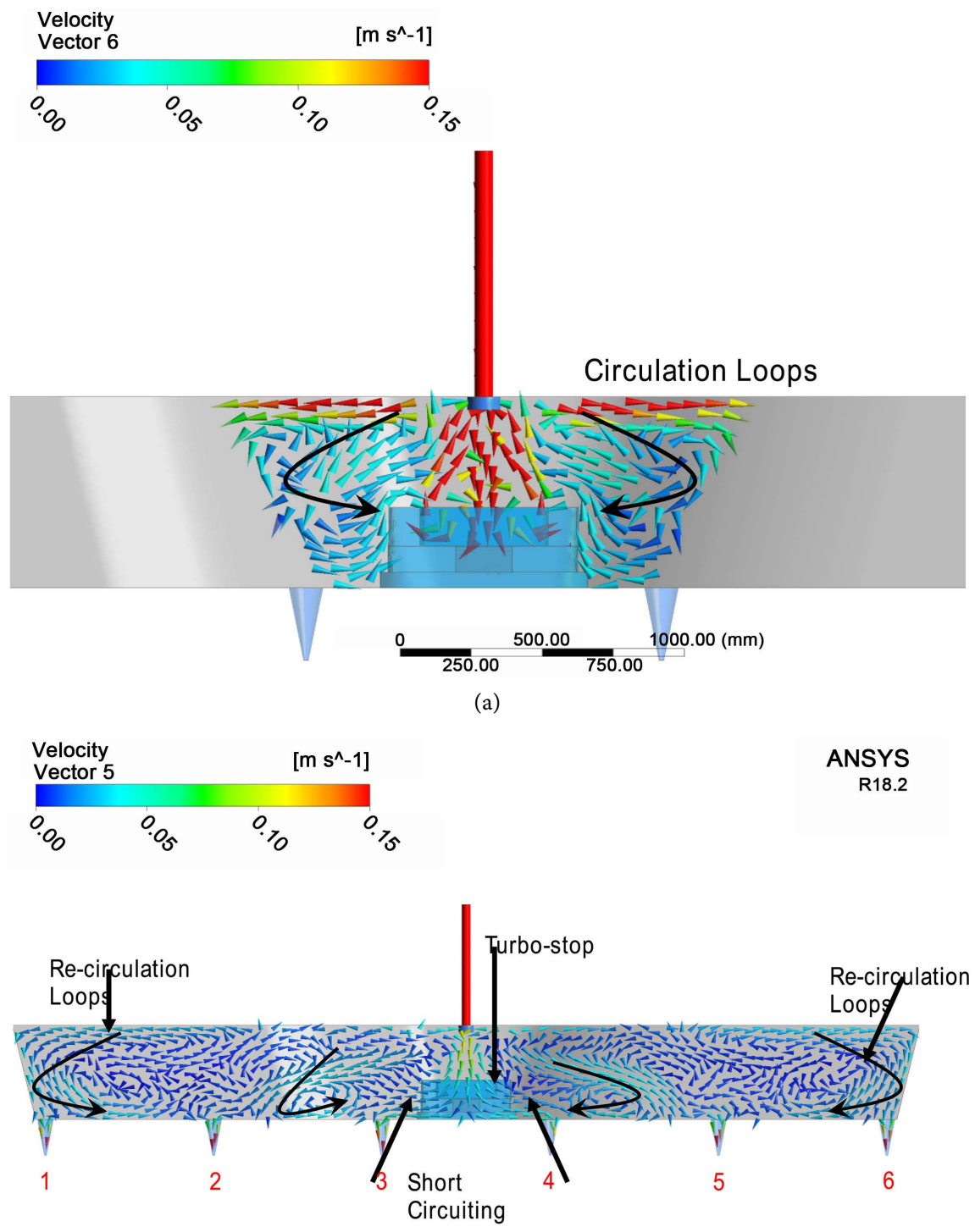

(b)

Figure 5. Velocity vectors at various locations in 6 strands Tundish all strand functional. (a) Velocity vector field on a plane passing through the inlet for 6 strand Tundish; (b) Velocity vector field on a plane passing through all outlets for 6 strand Tundish.
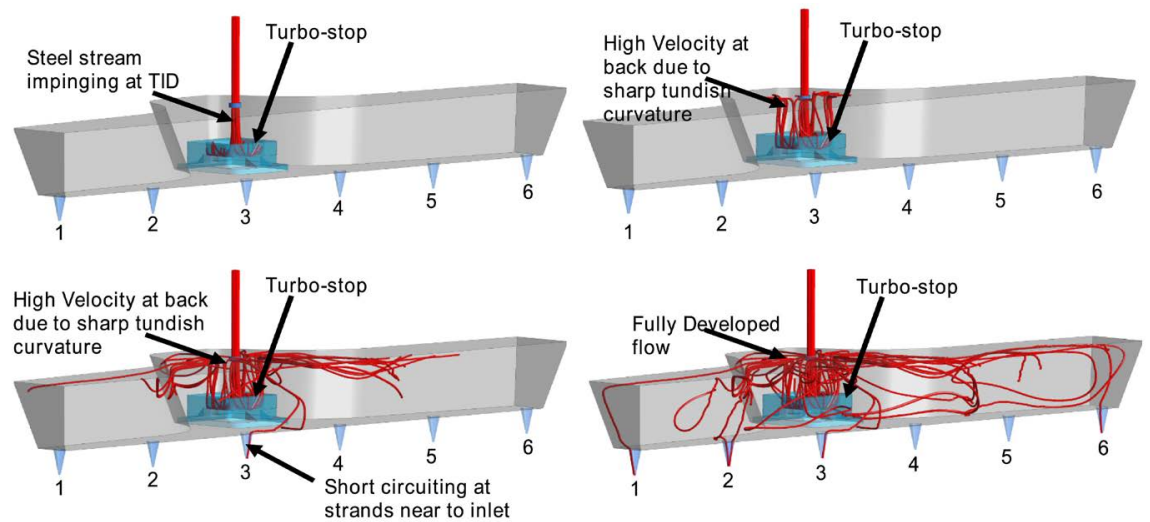

Figure 6. Streamline plot for 6 strands Tundish at various intervals. 
that the strands closest to the inlet are receiving the material first. This will have consequences in the grade transition and will be more evident during tracking of tracer which has been covered in the next section.

Figure 7(a) and Figure 7(b) show temperature distributions on two planes along the width passing through inlet and all the outlets, respectively. Overall, a maximum drop of temperature in the Tundish is about $10^{\circ} \mathrm{C}$. To compare temperature at different strands, the temperatures at all six strand outlets are shown in Figure 8 with respect to inlet temperature. As expected the farthest strand has highest temperature drop. Higher temperature is achieved in the nearest strands from the inlet. Predominantly two factors are responsible for this large temperature drop in the outer strands: first one is presence of numerous slow moving zones and seconds one is higher residence time. However, comparing nearest to the farthest strands regarding temperature drop, there is a minimal difference of $2^{\circ} \mathrm{C}$ in the temperature.

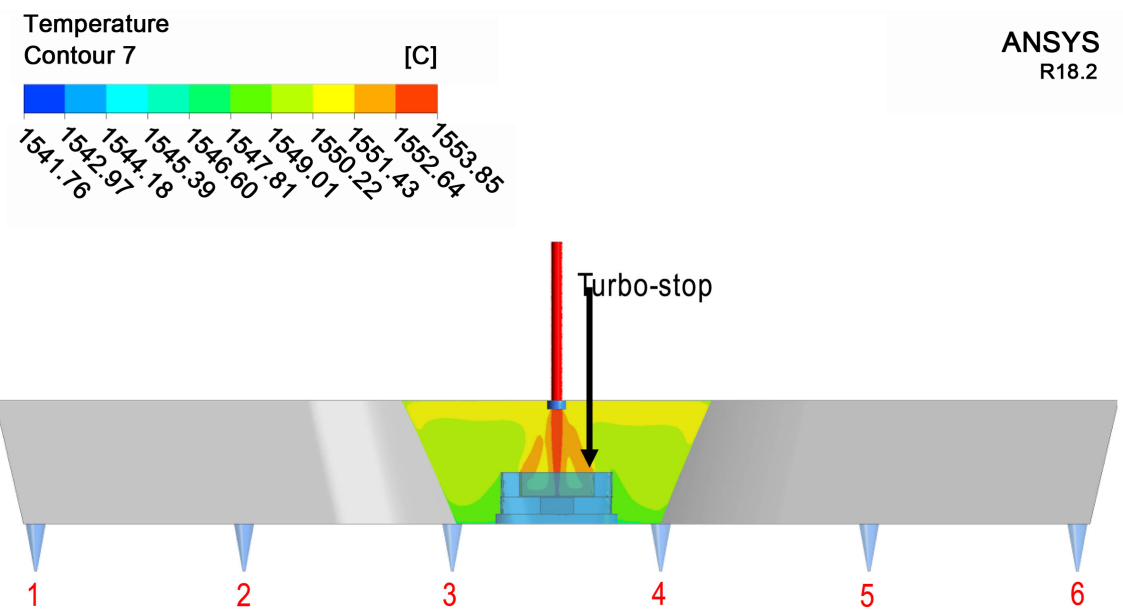

(a)

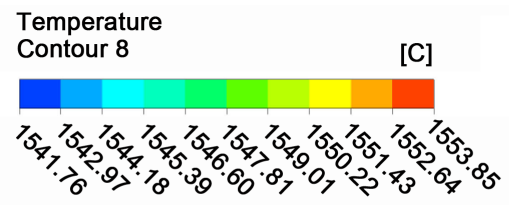

ANSYS

[C]

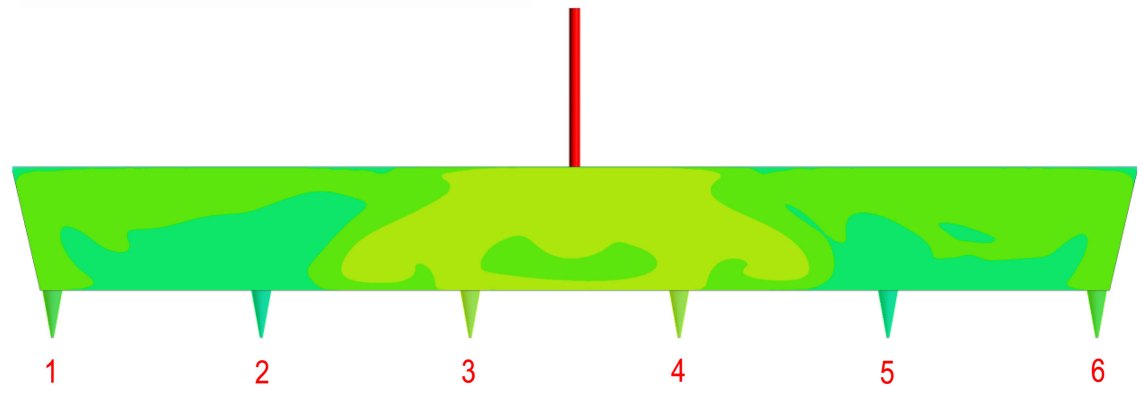

(b)

Figure 7. Temperature counters on various planes in 6 strands Tundish all strand functional. (a) Temperature field on a plane passing through the inlet for 6 strand Tundish; (b) Temperature field on a plane passing through all outlets for 6 strand Tundish. 


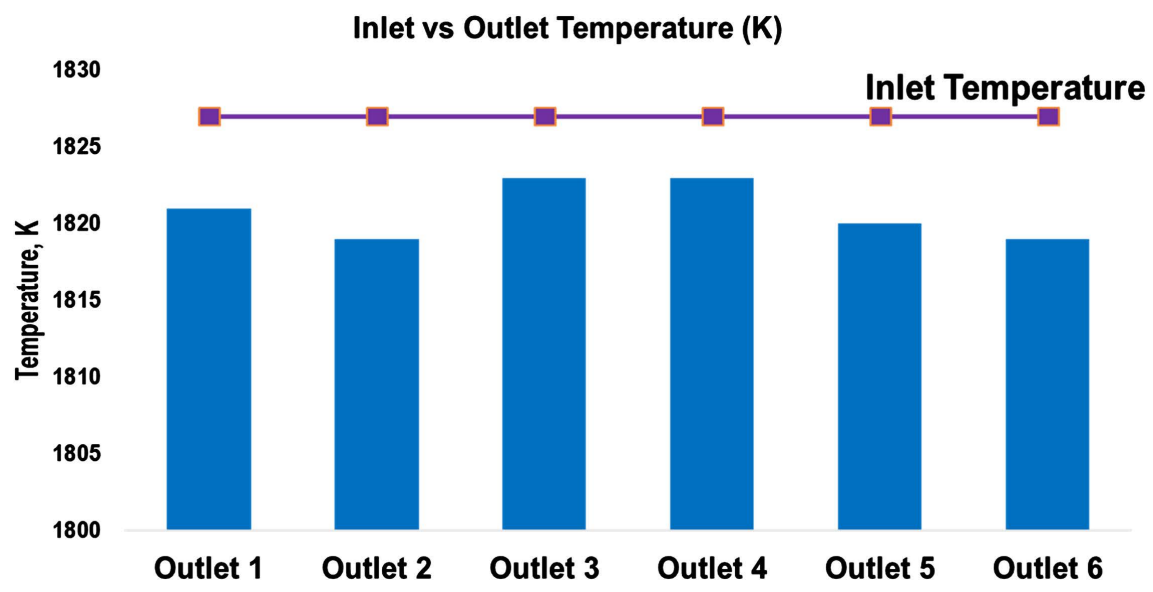

Figure 8. Comparison of Inlet temperature to outlet temperatures of strands for 6 strands Tundish all strands functional.

\subsection{Characteristics of Tundish}

\subsubsection{Residence Time Distribution (RTD) Curves}

To characterize Tundish behaviour, many authors [2] [21] have used plug flow, dead volume, and well-mixed regions also called RTD parameters. If the proportion of the well mixed region is higher, this indicates adequate mixing in the melt phase and hence better material and heat transport. On the other hand, a large plug flow volume indicates better possibility of inclusion floatation. In addition, higher the dead volume, higher will be the heat loss and higher the transition tonnage.

The RTD parameters are obtained from tracer concentration evolution as described in Section 3.1. Here analyses have been performed to find these parameters for 3 different scenarios: when all strands are working, when the one of the outermost strand is off ( $6^{\text {th }}$ off) and when one of the strands closest to inlet is off ( $4^{\text {th }}$ off). To find a single RTD curve for a given Tundish, Tracer concentrations at respective outlets (strands) are averaged with respect to number of strands. Figure 9 presents the dimensionless RTD plot for above mentioned three scenarios. The corresponding RTD values are presented in Table 3. The data about volumes shows that when one of the strands is non-functional, the dead volume increases while plug flow volume decreases.

It will also be interesting to find if above volumes was impacted by change in casting speed. Table 4 compares these volumes for 3 and $3.5 \mathrm{~m} / \mathrm{min}$ casting speed. There is insignificant impact of casting speed change on the volumes. In other words, increase or decrease in casting speed does not change the characteristics of the Tundish.

\subsubsection{Prediction of Grade Transition}

Figure 10(a) shows the concentration plot (E-Curve) with respect to time for two strands, strand 4 (nearest to the inlet) and strand 1 (farthest from the inlet). Looking at Figure 10(a), it is evident that nearest strand is receiving the material first (red curve in the figure) as well as the decay rate for this strand is faster. 


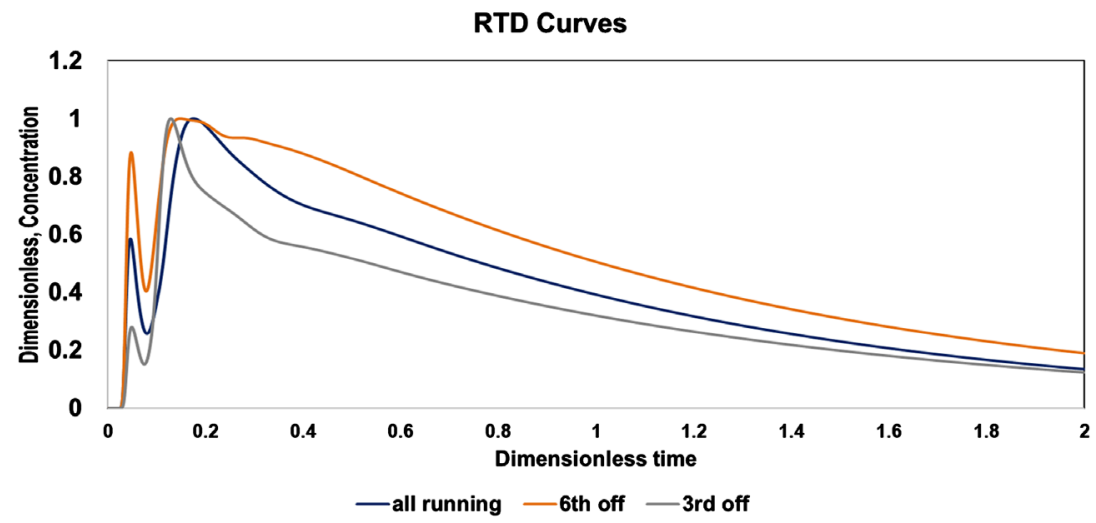

Figure 9. RTD curves for different strand operational on dimensionless concentration with dimensionless time.

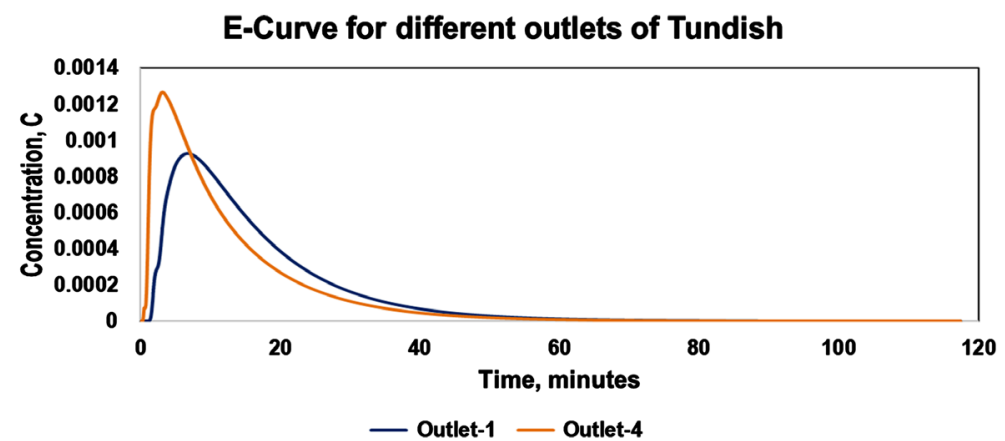

(a)

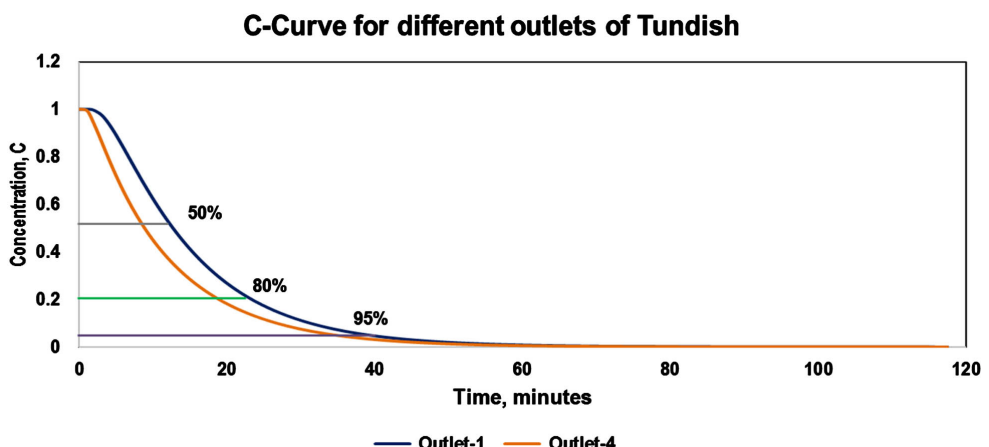

(b)

Figure 10. Prediction of grade transition at different level (50\%, 80\% and 95\%) for 6 strands Tundish. (a) E-Curve for strand 1 and 4; (b) Normalized concentration curve for strand 1 and 4.

Table 3. Comparison of RTD parameters of Tundish for different plant scenarios.

\begin{tabular}{ccccc}
\hline & & $\begin{array}{c}\text { All } \\
\text { strand working }\end{array}$ & $\begin{array}{c}\mathbf{6}^{\text {th }} \\
\text { strand off }\end{array}$ & $\begin{array}{c}3^{\text {rd }} \\
\text { strand off }\end{array}$ \\
\hline$\theta_{\text {min }}$ & Dimensionless minimum residence time & 0.05 & 0.025 & 0.02 \\
$\theta_{\text {mean }}$ & Dimensionless mean residence time & 0.72 & 0.63 & 0.55 \\
$\mathrm{~V}_{\text {Dead }}(\%)$ & Dead volume & 25.65 & 37.6 & 41.87 \\
$\mathrm{~V}_{\text {DPlug }}(\%)$ & Dispersed plug flow volume & 32.25 & 25.11 & 16.44 \\
$\mathrm{~V}_{\text {mix }}(\%)$ & Well mixed volume & 42.1 & 37.8 & 41.01 \\
\hline
\end{tabular}


Table 4. Comparison for RTD for different casting speed.

\begin{tabular}{ccc}
\hline & $\begin{array}{c}\text { All strand working } \\
\text { (casting speed: } \mathbf{~ m / m i n} \text { ) }\end{array}$ & $\begin{array}{c}\text { All strand working } \\
\text { (casting speed: 3.5 m/min) }\end{array}$ \\
\hline Plug flow region (\%) & 17.51 & 17.82 \\
Dead regions (\%) & 28.70 & 27.16 \\
Well mixed region (\%) & 53.73 & 55.08 \\
\hline
\end{tabular}

This shows short-circuiting phenomenon as mentioned in literature [7] [10] and as obvious from streamline plots (see Figure 6).

To predict the transition tonnage during the grade change, the exit age distribution, E-curve, obtained for each strand is normalized on the scale of 0 to 1 by using Equation (8), Equation (9) and Equation (10). The curve thus obtained is called C-curve as shown in Figure 10(b). This C-curve forms the basis of the prediction of transition tonnage [7]. The transition time and tonnage obtained depends on the composition difference of the grades and acceptance criteria at plant. For example, transition can finish at $50 \%$ or $80 \%$ or $95 \%$ as indicated by horizontal lines in the plot of Figure 10(b), is solely dictated by customer requirement.

In real plant scenario, transition tonnage is predicted by comparing transition of critical elements (e.g. C, Mn, Si, Cr, Vetc.) during grade change. This requires transition percentage to be calculated based on the limiting element. Based on the band of acceptable composition of a grade (e.g. 80\%, 90\%, 95\%), the corresponding transition time and transition tonnage is predicted.

As shown in Figure 10(b), the transition time for strand 4 is lesser than strand 1. Here in LD\#1 CC3 caster, the strand with largest transition time (strand 1 or 6) is the limiting strand. This is because the torch cutting system of billets has certain limitations in its automation system. However, there is a possibility to automate the transition cutting system for each strand to minimize losses.

\subsubsection{Validation of the Grade Transition Model}

To get the confidence in the grade transition model, a plant trial was executed. The trial casting conditions and grade composition are shown in Table 5 and Table 6. In the trial, all the strands were functional and average casting speed was in range of $2.71 \mathrm{~m} / \mathrm{min}$. Strand 6 was chosen for sampling of billets to track the chemistry variation of elements $[\mathrm{C}, \mathrm{Mn}, \mathrm{Si}]$ with respect to casting time. Nine billet samples were collected from the strand 6 at different time intervals after the Grade 2 ladle was opened to be poured into the Tundish. Table 7 shows the variation of $\mathrm{Mn}, \mathrm{Si}$ and $\mathrm{C}$ concentration (both normalized and non-normalized) with respect to casting time. As it is evident from Table 7 that the critical element for the trial sequence is $\mathrm{Mn}$ since the transition of $\mathrm{Mn}$ is slowest among all elements. The normalized concentrations obtained from both CFD and plant is compared as shown in Figure 11. The transition time to achieve $92 \%$ of 


\section{Validation with Plant}

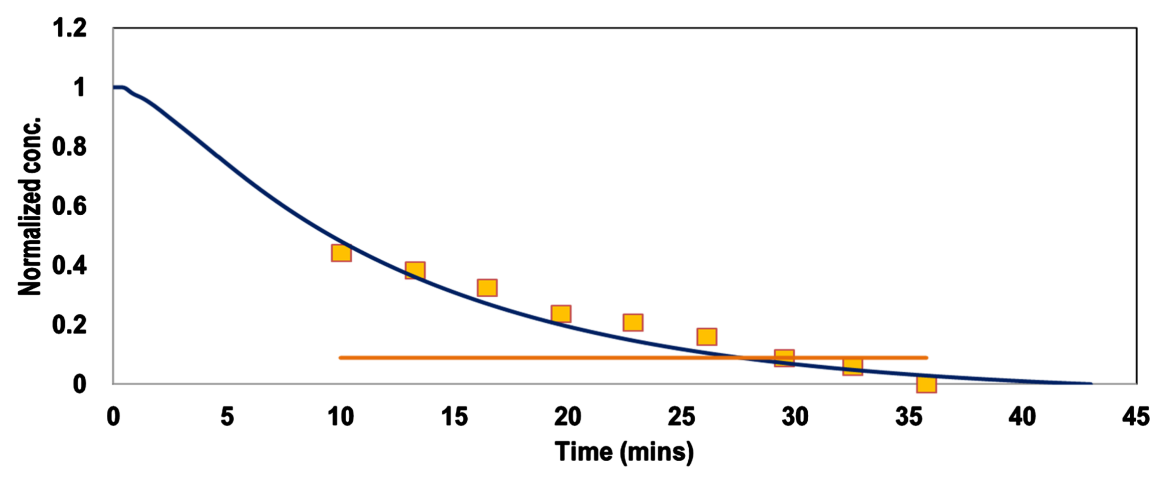

$\square$ Analysis of Mn from exp - C- curve for outlet 6

Figure 11. Validation for 6 strands Tundish with experimental data points.

Table 5. Grades used for validation during plant experiment.

\begin{tabular}{ccc}
\hline & Grade1 & Grade2 \\
\cline { 2 - 3 } & PC No. 479-M75480 & PC No. 975-Heat Id M75483 \\
\hline Critical element-Carbon & $0 \%-0.06 \%$ & $0.0 \%-0.07 \%$ \\
Actual \% C & $0.03 \%$ & $\mathbf{0 . 0 6 8 \%}$ \\
Critical element-Manganese & $0.5 \%-0.55 \%$ & $0.27 \%-0.35 \%$ \\
Actual \% Mn & $\mathbf{0 . 5 0 4 \%}$ & $\mathbf{0 . 3 3 5 \%}$ \\
Critical element-Silicon & $0.018 \%-0.028 \%$ & $0.035 \%-0.07 \%$ \\
Actual \% Si & $\mathbf{0 . 0 2 4 \%}$ & $\mathbf{0 . 0 4 7 \%}$ \\
\hline
\end{tabular}

Table 6. Casting speed for each strand during plant experiment.

\begin{tabular}{ccccccc}
\hline Casting Speed, $\mathrm{m} / \mathrm{min}$ (Avg.) & Strd1 & Strd2 & Strd3 & Strd4 & Strd5 & Strd6 \\
\hline Tundish weight at ladle open $=23.7 \mathrm{~T}$ & 2.71 & 2.71 & 2.71 & 2.71 & 2.71 & 2.71 \\
\hline
\end{tabular}

Table 7. Elements variation with time during plant experiment.

\begin{tabular}{ccccccc}
\hline \multirow{2}{*}{$\begin{array}{c}\text { Time } \\
\text { (mins) }\end{array}$} & Non-Normalized \% & Normalized & Non-Normalized \% & Normalized & Non-Normalized \% & Normalized \\
\cline { 2 - 7 } 10 & 0.06 & 0.741935 & 0.4 & 0.443 & 0.032 & 0.653846 \\
13.25 & 0.06 & 0.741935 & 0.39 & 0.384 & 0.034 & 0.576923 \\
16.41 & 0.054 & 0.548387 & 0.375 & 0.325 & 0.034 & 0.5 \\
19.66 & 0.053 & 0.516129 & 0.37 & 0.236 & 0.039 & 0.5 \\
22.83 & 0.06 & 0.741935 & 0.362 & 0.207 & 0.039 & 0.307692 \\
26.083 & 0.06 & 0.741935 & 0.35 & 0.159 & 0.04 & 0.307692 \\
29.5 & 0.044 & 0.225806 & 0.345 & 0.088 & 0.043 & 0.269231 \\
32.5 & 0.042 & 0.16129 & 0.335 & 0.059 & 0.043 & 0.153846 \\
35.75 & 0.039 & 0.064516 & 0.4 & 0 & 0.043 & 0.153846 \\
\hline
\end{tabular}


transition according to CFD analysis is around 28 minutes while plant trial composition variation reveals it is around 29.5 minutes. Looking at the validation plot (Figure 11), a good match between numerical model and plant data can be established. This provides a good confidence in the model to analyse different plant scenarios. The next section will be presenting different plant conditions regarding grade transition.

\section{Prediction of Transition Tonnage for Different Plant Condition}

In this section, various ifs and buts for numerous plant conditions will be presented. Due to breakout or other mechanical failures of strands during casting, numerous scenarios may prevail. For example, outer strand may become non-functional or one of the inner strands may be closed or any of the two strands may become non-functional. As known from previous section about RTD analysis that the closure of strands with respect to inlet position changes the flow characteristics as well as RTD features. Therefore, it is suspected that the above scenarios may impact the transition tonnage generated during the grade change. To understand that, here numerous situations are analysed. This exercise in essence can provide a guideline to plant in taking proper action to cut the transition tonnage at accurate time. In addition, casting speed during grade change may vary. This also needs a deep evaluation to find if there is impact of casting speed on grade transition tonnage or not.

\subsection{Grade Transition Based on Strand Availability}

As stated earlier during casting operation, there is a possibility that certain strands are not operational. Here three scenarios are analysed for the six strands Tundish: first case where all 6 strands are functional, second case where number 6 strand is non-functional (farthest from the inlet) and the third case where number 4 strand is non-functional (nearest from the inlet), for nomenclature of strands see Figure 1(b). Note that here casting speed is fixed and taken as 3.1 $\mathrm{m} / \mathrm{min}$ and Tundish weight is 28 Tons (total content of liquid steel in the Tundish). The casting speed remains same $(3.1 \mathrm{~m} / \mathrm{min})$ defined at outlet of strand (for closure of one strand case) and hence total input (mass flow rate) to Tundish is scaled by number of strands functional. The strands are made non -functional by defining one of the outlets as wall during the simulation.

Note that the casting speed and the weight of the steel in Tundish are based on real plant scenario. The transition tonnage is calculated as follows:

Transition Tonnage $=$ casting speed $\times$ density of steel $\times$ area of the billet $x$ transition time $\times$ No. of strands running

To predict transition tonnage for different plant scenarios, numerous permutations and combinations for strand unavailability is analysed. Figure 12 compares the transition tonnage and time for the cases where anyone or any two strands are non-functional. For single strand closure, the highest transition 


\section{Tundish Transition Time}

Casting Speed:3m/min

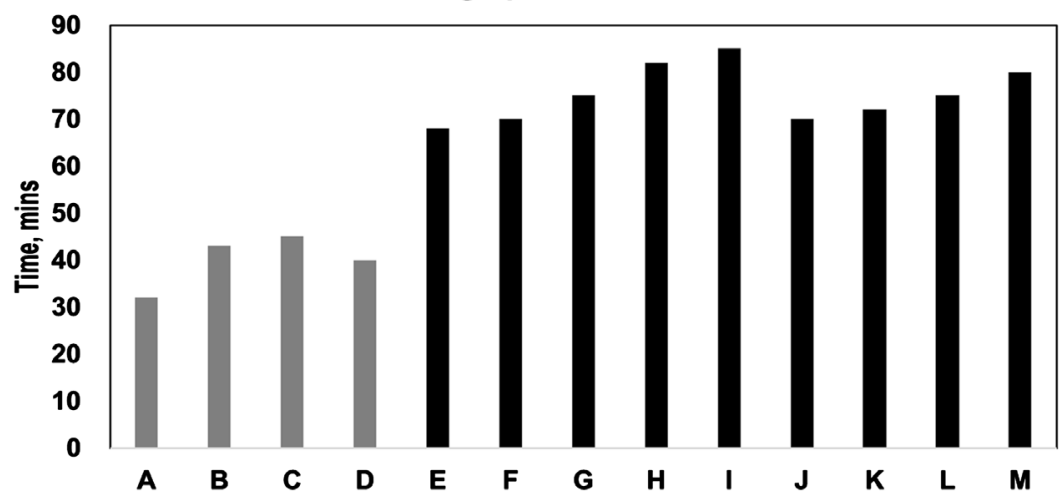

(a)

\section{Tundish Transition Tonnage Casting Speed:3m/min}

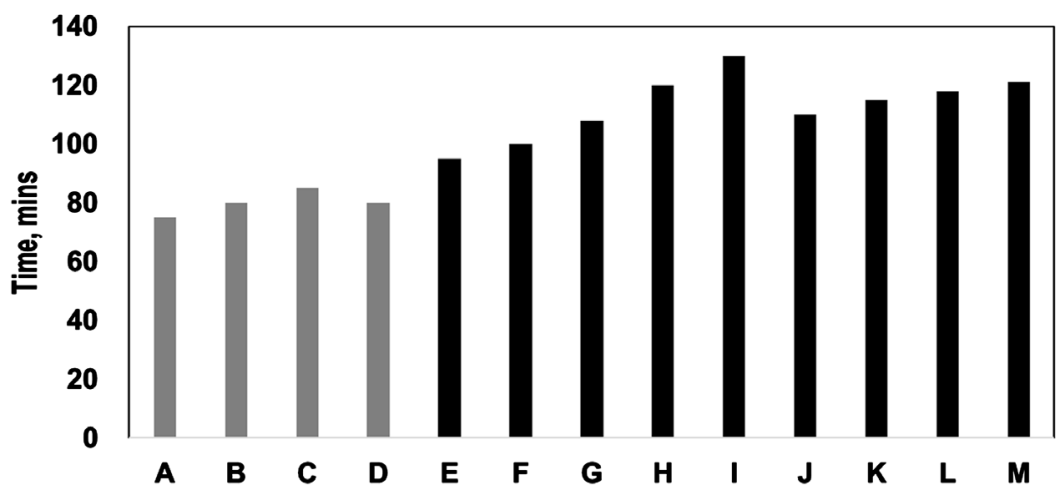

(b)

Figure 12. Comparison of transition time and tonnage for 6 strands Tundish under different plant scenario. (a) Transition time for 6 strands Tundish for all strand running scenario; (b) Transition tonnage for 6 strands Tundish for all strand running scenario. Symbol: Case. A: All strand functional; B: $1^{\text {st }}$ strand off; C: $3^{\text {rd }}$ strand off; D: $2^{\text {nd }}$ strand off; E: $1^{\text {st }}$ and $4^{\text {th }}$ strand off; F: $2^{\text {nd }}$ and $4^{\text {th }}$ strand off; G: $2^{\text {nd }}$ and $3^{\text {rd }}$ strand off; H: $1^{\text {st }}$ and $6^{\text {th }}$ strand off; I: $3^{\text {rd }}$ and $4^{\text {th }}$ strand off; J: $1^{\text {st }}$ and $5^{\text {th }}$ strand off; K: $2^{\text {nd }}$ and $5^{\text {th }}$ strand off; L: $1^{\text {st }}$ and $3^{\text {rd }}$ strand off; M: $1^{\text {st }}$ and $2^{\text {nd }}$ strand off.

tonnage is produced when closest strand to the inlet, strand (3 or 4) is non-operational. For two strand closure cases, the strand 1 and 2 closure leads to highest transition tonnage.

\subsection{Impact of Casting Speed on Grade Transition}

A pertinent question is that whether at different casting speed, the transition time and tonnage will be different. To answer this, transition tonnage and time is computed for two casting speeds, 3 and $3.5 \mathrm{~m} / \mathrm{min}$ for all strand working scenario. Figure 13 shows a comparison of transition time and tonnage based on limiting strand (strand 1 and 6 farthest). As evident that the increase in casting speed from 3 to $3.5 \mathrm{~m} / \mathrm{min}$ decreases the transition time from 44.3 to $37 \mathrm{~min}$ utes, while change in transition tonnage is insignificant ( 80.1 to 78.5 tons). For 
Transition Time based on Limiting Strand

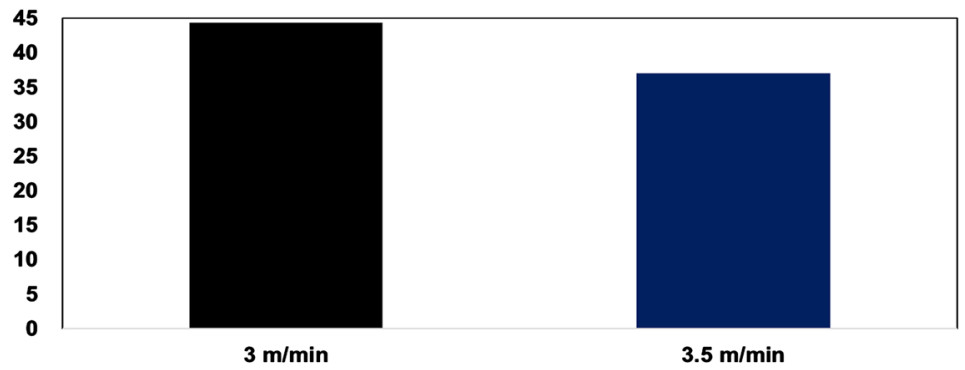

(a)

Transition Tonnage based on Limiting Strand

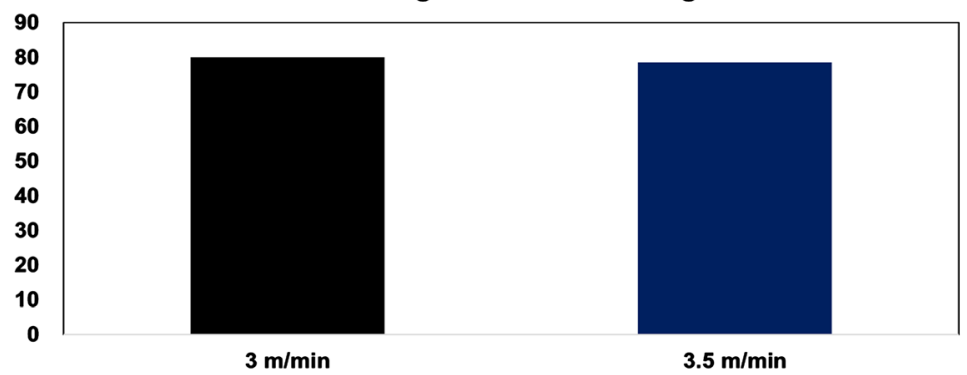

(b)

Figure 13. Comparison transition plot for 6 strands Tundish with different casting speed. (a) Comparison based on transition time; (b) Comparison based on transition tonnage.

the operational people, transition tonnage is the deciding factor to remove the mixed composition. It can be stated that the CC\#3 Tundish has nominal impact on transition tonnage due to increase in casting speed. The above fact essentially tells that there is no change in flow characteristics of Tundish due to change in casting speed. This was already obvious from the analysis of dead, plug and well mixed volume in Section 5.2.1 where no significant impact on the volumes was found due to change in the casting speed. Hence, this signifies that no. of rounds of billets which will be downgraded for transition remains same irrespective of casting speed.

\section{Effect of Baffles (Flow Modifiers) on the Performance of Tundish}

There is always an emphasis to decrease the intermixed quantity. One of the methods is to provide special baffles. To study the impact of baffles on the transition tonnage, here two types of design of baffles for six strands Tundish have been performed. The two designs are shown in Figure 14 (say design 1) and Figure 15 (say design 2) respectively. The Design 1 (Figure 15) presents a design of Tundish, in which two dams are placed across the width of Tundish adjacent to the turbo-stop. The Design 2 (Figure 16) presents the design of Tundish in which a single long dam is made between inlet and outlet, the dam is placed just in front of the turbo-stop. The height of the dam is taken to be half height of Tundish height. Both the new designs were simulated for the same casting speed of $3.1 \mathrm{~m} / \mathrm{min}$. 


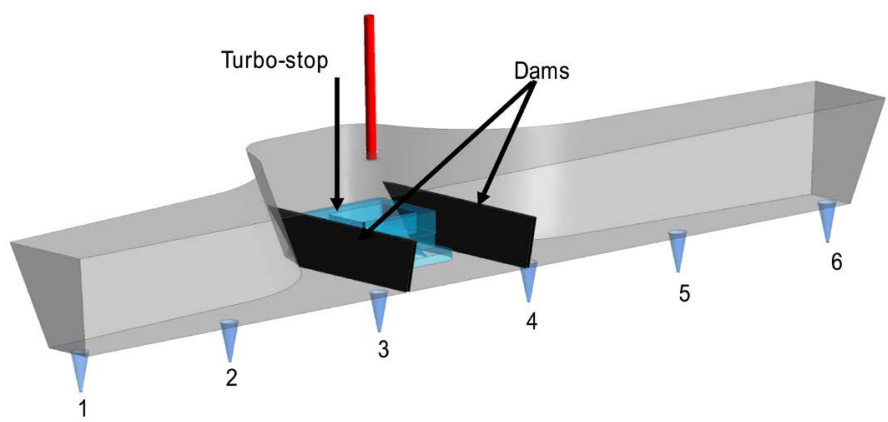

(a)

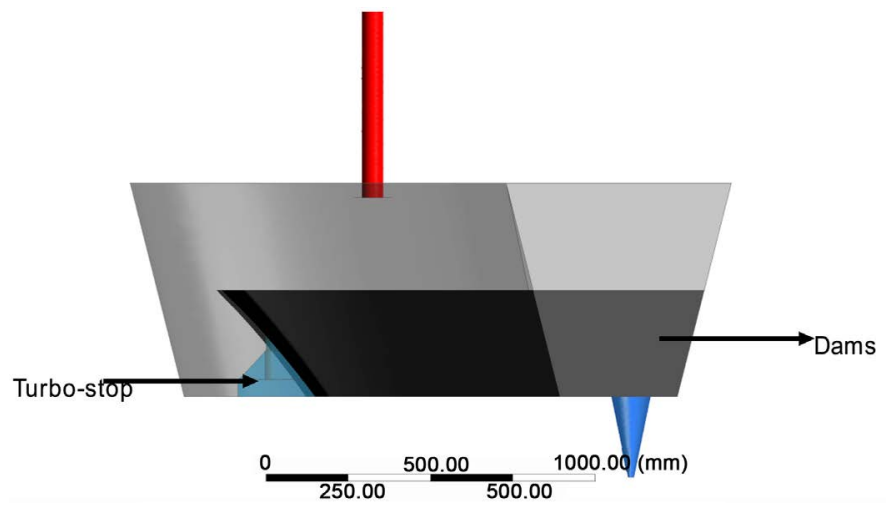

(b)

Figure 14. Tundish design with two symmetrical baffles (Design 1). (a) Iso-view of Tundish with 2 dams; (b) Side view of Tundish with 2 dams.

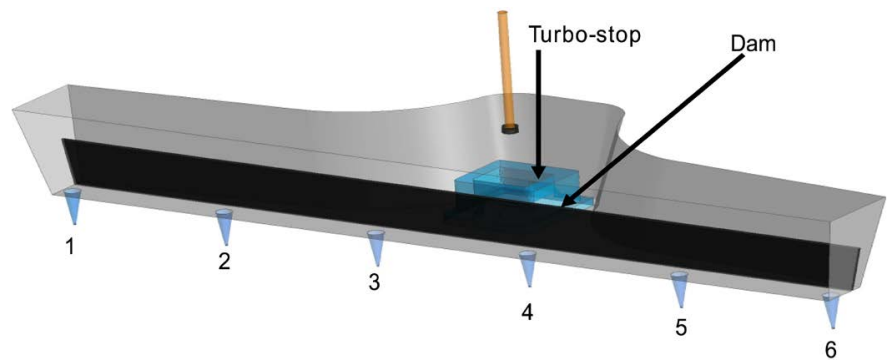

(a)

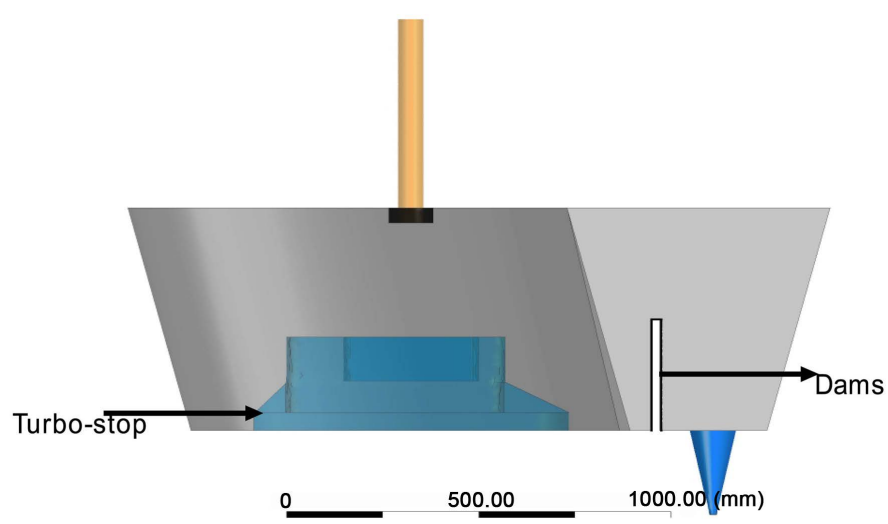

(b)

Figure 15. Tundish design with long baffle (Design 2). (a) Iso-view of Tundish with long dam; (b) Side view of Tundish with 1 long dams. 


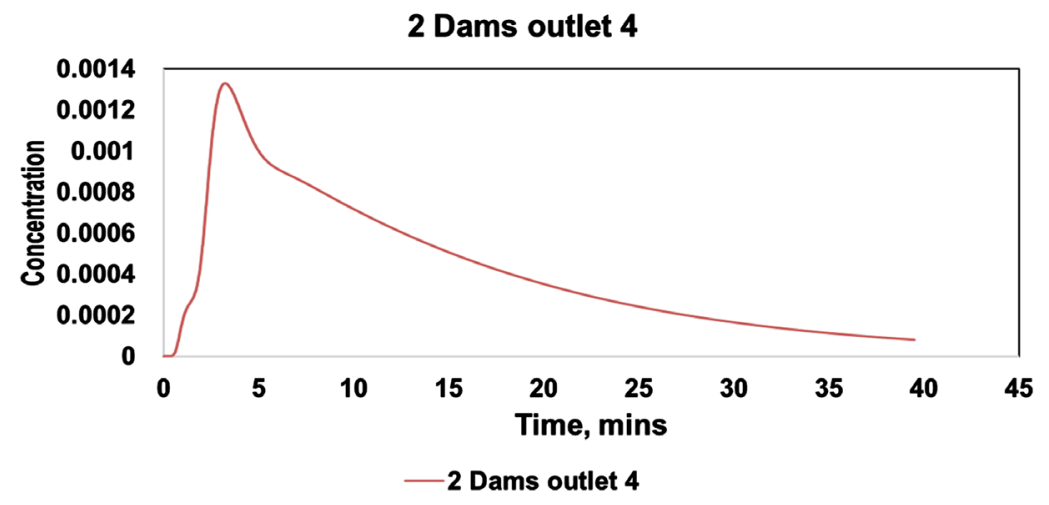

(a)

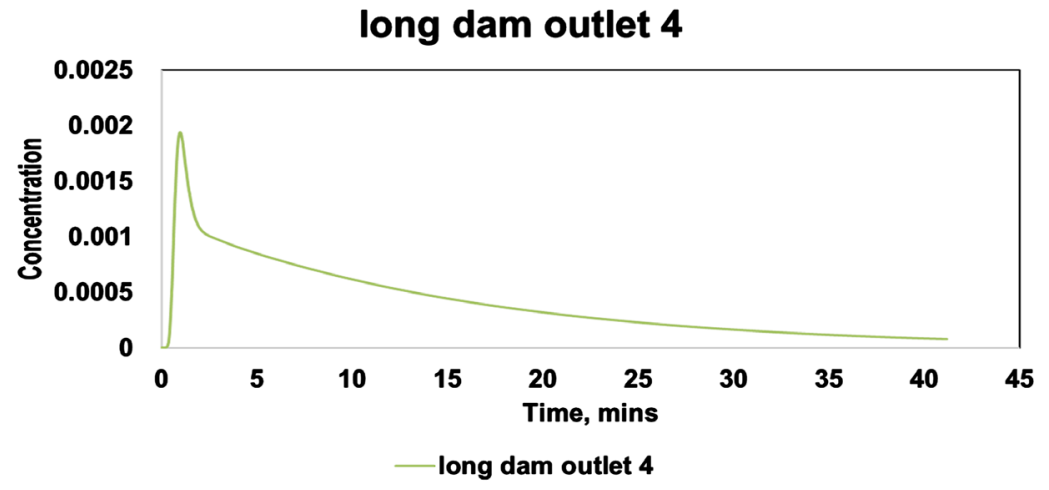

(b)

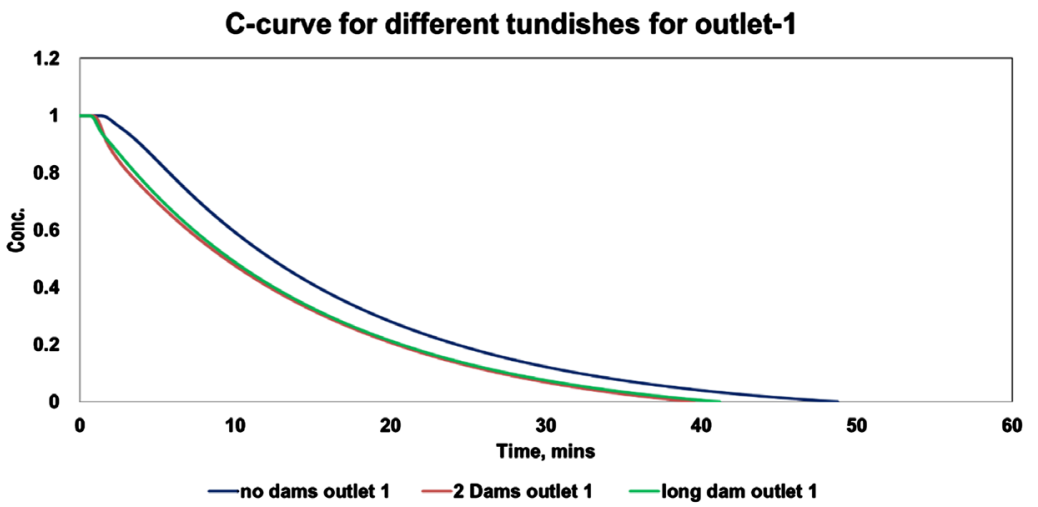

(c)

Figure 16. Effects of baffles on the performance of Tundish. (a) RTD curve for strands 1 and 4 for two baffle Tundish; (b) RTD curve for strands 1 and 4 for long baffle Tundish; (c) Transition time prediction for different Tundish designs (no dams, single long dam and 2 dams).

To understand the impact of short circuiting, Figure 16(a) and Figure 16(b) are plotted. Figure 16(a) and Figure 16(b) show the RTD curves for Design 1 and Design 2 respectively for strands 1 and 4. When comparing Figure 16(a) and Figure 16(b) (Tundish design with baffles) with Figure 10(a) (Tundish without baffles), it is evident that short-circuiting is diminished by introducing baffles in the Tundish.

Figure 16(c) shows the concentration plot for Tundish with no baffle, Tun- 
dish with 2 symmetric baffles (Design 1) and one long baffle (Design 2). The transition times for Tundish without baffle, Design 1 and Design 2 are 48, 39.5 and 41.1 minutes respectively. It is clear that the Tundish with 2 baffles (Design 1) is best for productivity increase by decreasing the intermixed quantity.

On calculating the tonnage saving for Tundish with 2 baffles (Design 1) reveals that 21 tons material ( 3 rounds of $9 \mathrm{~m}$ billet) can be prevented from downgradation or diversion. This is a huge saving.

\section{Conclusions}

In this study, a model to predict transition tonnage and time for 6 strand billet caster Tundish of Tata Steel India has been developed using CFD methodology. The developed model in this study validates quite well with the plant trial findings. The model has been used to analyse different plant conditions e.g. if nearest strand to inlet or farthest strand to inlet has been non-operational; then what will be the impact on transition tonnage. The model has shown its efficacy to provide insights about what happens during grade change. The important conclusions from this study are outlined as follows:

- Flow field inside the Tundish is symmetrical and short circuiting phenomena are observed to happen for a strand nearest to inlet.

- Due to special curved design near inlet, high surface velocity regions directed towards long side wall away from strand outlets are found. This may lead to heavy erosion of Tundish refractory in the top region of rear wall area.

- The closure of the one or more strands plays a vital role for dictating the transition tonnage to be downgraded.

- For single strand closure situation, highest transition tonnage is produced when strand nearest to inlet is non-functional and minimum transition tonnage is achieved when all strands are functional.

- Casting speed plays a role in reducing transition time, but it does not have significant impact on transition tonnage. This was due to the fact that insignificant changes in the plug, dead and well mixed zones were found due to increase or decrease in the casting speed.

- Baffles improve the performance of Tundish and reduce the intermixed quantity.

A future study is underway to find the best baffle height, number of baffles and position of baffles to further reduce the intermixed quantity.

\section{Acknowledgements}

The authors are thankful to Tata Steel India Management for their support for carrying out research.

\section{Conflicts of Interest}

The authors declare no conflicts of interest regarding the publication of this paper. 


\section{References}

[1] Chattopadhyay, K., Issac, M. and Guthrie, R.I.L. (2010) Physical and Mathematical Modelling of Steelmaking Tundish Operations: A Review of the Last Decade (1999-2009) ISIJ International, 50, 331-348. https://doi.org/10.2355/isijinternational.50.331

[2] Mazumdar, D. and Evans, J.W. (2009) Modelling of Steel Making Processes. CRC Press, New York, 493.

[3] Thomas, B.G. (1997) Modelling Study of Intermixing in Tundish and Strand during a Continuous-Casting Grade Transition. Iron and Steelmaker (ISS Transactions), 24, 83-96. https://pdfs.semanticscholar.org/47da/3ff65fce386675eb76484868329e13e1bd3f.pdf

[4] Cho, M.J. and Kim I.C. (2006) Simple Tundish Mixing Model of Continuous Casting during a Grade Transition. ISIJ International, 46, 1416-1420.

https://doi.org/10.2355/isijinternational.46.1416

[5] Huang, X. and Thomas, B.G. (1996) Intermixing Model of Continuous Casting during a Grade Transition. Metallurgical and Materials Transactions B, 27, 617-632. https://doi.org/10.1007/BF02915660

[6] Goldschmit, M.B., Ferro, S.P., Walter, G.F., Aranda, V.G. and Morelos, J.A.T. (2001) Numerical Model for the Minimization of Intermixed Round Bars in a Four-Line Continuous Caster. Metallurgical and Materials Transactions B, 32, 537-546. https://doi.org/10.1007/s11663-001-0038-2

[7] Merder, T. and Marek, W. (2012) Optimization of a Six-Strand Continuous Casting Tundish: Industrial Measurements and Numerical Investigation of the Tundish Modifications. Metallurgical and Materials Transactions B, 43, 856-868.

https://doi.org/10.1007/s11663-012-9662-2

[8] Chen, C., Jonsson, L.T.I., Tilliander, A.,Cheng, G. and Jönsson, P.G. (2015) A Mathematical Modeling Study of Tracer Mixing in a Continuous Casting Tundish. Metallurgical and Materials Transactions B, 46, 169-190. https://doi.org/10.1007/s11663-014-0190-0

[9] Merder, T. (2012) Numerical Simulation of Liquid Flow and Mixing Steel in Multi-Strands Tundish. Journal of Achievements in Materials and Manufacturing Engineering, 55, 561-566.

[10] Gupta, S. and Dewan, A. (2013) Performance Optimization of a Six-Strand Tundish. World Journal of Mechanics, 3, 184-193.

[11] Jha, P.K. and Dash, S.K. (2002) Effect of Outlet Positions and Various Turbulence Models on Mixing in a Single and Multi-Strand Tundish. International Journal of Numerical Methods for Heat \& Fluid Flow, 12, 560-584. https://doi.org/10.1108/09615530210434296

[12] Thakre, B., Kothare, C.B. and Raizada, K.S. (2015) Thermal Analysis of Tundish in Continuous Casting Machine in Steel Industry: A Review. International Research Journal of Engineering and Technology (IRJET), 2, 255-288.

[13] Dewan, A. (2011) Tackling Turbulent Flows in Engineering. Springer, Berlin. https://doi.org/10.1108/09615530210434296

[14] Mazumdar, D. (2013) Tundish Metallurgy: Towards Increased Productivity and Clean Steel. Transactions of the Indian Institute of Metals, 66, 597-610. https://doi.org/10.1007/s12666-013-0305-3

[15] Kanse, N. G. and Dawande, S.D. (2012) RTD Studies in Plug Flow Reactor and Its Simulation with Comparing Non-Ideal Reactors. Research Journal of Recent Sci- 
ences, 1, 42-48. http://www.isca.in/rjrs/archive/v1/i2/5ISCA-RJRS-2012-025.pdf

[16] Thomas, B. (1997) Advanced Physical Chemistry for Process Metallurgy. Academic Press, Cambridge, 253-279.

[17] Tripathi, A. and Ajmani, S.K. (2005) Effect of Shape and Flow Control Devices on the Fluid Flow Characteristics in Three Different Industrial Six Strand Billet Caster Tundis. ISIJ International, 45, 1616-1625.

https://doi.org/10.2355/isijinternational.45.1616

[18] (2006) Fluent User Guide. Fluent Inc., Lebanon. http://jullio.pe.kr/fluent6.1/help/pdf/ug/fl61ug.pdf

[19] Siddiqui, M.I.H. and Jha, P.K. (2014) Grade Mixing Analysis in Steelmaking Tundish Using Different Turbulence Models. 5 th International \& 26 th All India Manufacturing Technology, Design and Research Conference, Assam, 12-14 December 2014, 1-6.

[20] Siddiqui, M.I.H. and Jha, P.K. (2014) Assessment of Turbulence Models for Prediction of Intermixed Amount with Free Surface Variation Using Coupled Level-Set Volume of Fluid Method. ISIJ International, 54, 2578-2587.

[21] Hackl, G., Heinrich, B., Nitzl, G. and Meurer, D. (2017) Characterization of Novel Flow Control Refractories for the Continuous Casting Process by Modelling and Simulation. AISTech Conference Proceedings, Nashville, 8-11 May 2017, 1817-1825. http://digital.library.aist.org/pages/PR-372-301.htm 